\section{Estudo \\ Ecidebate}

em Cestão

Plamejamento
Revista Estudo \& Debate, Lajeado, v. 23, n. 2, 2016. ISSN 1983-036X

DOI: http://dx.doi.org/10.22410/issn.1983-036X.v23i2a2016.1079

\title{
A EDUCAÇÃO AMBIENTAL NA PERSPECTIVA DA GESTÁO ESCOLAR NO VALE DO TAQUARI/RS/BRASIL
}

\author{
Daiani Clesnei da Rosa ${ }^{1}$, Odorico Konrad ${ }^{2}$, Márcia Jussara Hepp Rehfeldt ${ }^{3}$
}

\begin{abstract}
Resumo: Este artigo busca promover discussão sobre o ensino de educação ambiental na perspectiva da gestão escolar, por meio de reflexôes acerca da educaçáo ambiental crítica na construção da cidadania, e da gestáo democrática e participativa. Esta é uma pesquisa com abordagem quali-quantitativa, descritiva e exploratória, bibliográfica e de levantamento, tendo utilizado como instrumento de coleta de dados um questionário, aplicado a 52 diretores de escolas estaduais, pertencentes à $3^{\text {a }}$ Coordenadoria Regional de Educaçáo (CRE), no Vale do Taquari/RS - Brasil. As informaçôes obtidas apontam que: a) a gestáo escolar exerce papel importante na promoçáo do ensino, por meio do acompanhamento do trabalho pedagógico dos docentes; b) a gestáo escolar como desencadeadora do processo democrático e participativo dentro das escolas promove a possibilidade de desenvolvimento da conscientização dos atores da comunidade escolar.
\end{abstract}

Palavras-chave: Educação ambiental. Gestão Escola. Ensino e Perspectivas.

\section{ENVIRONMENTAL EDUCATION IN THE PERSPECTIVE OF SCHOOL MANAGEMENT IN THE TAQUARI VALLEY/RS/BRAZIL}

Abstract: This paper aims to promote a discussion on the teaching of environmental education from the school management perspective, through reflections on critical environmental education in the construction of citizenship, and participative and democratic management. This is a qualitative-quantitative, descriptive and exploratory, bibliographical and survey research, using a questionnaire as data collection instrument applied to 52 state school principals belonging to the 3rd CRE in the Taquari Valley / RS - Brazil. Results indicate that: (a) school management plays an important role in the promotion of education through pedagogical support

1 Doutora em Ciências: Ambiente e Desenvolvimento, do Programa de Pós-Graduação em Ambiente e Desenvolvimento do Centro Universitário UNIVATES, mestra em Educação pela Universidade do Vale dos Sinos (UNISINOS) e graduada em Pedagogia pela UNISINOS. Professora no Centro Universitário UNIVATES. Email: dcrosa@univates.br.

2 Doutor em Engenharia Ambiental e Sanitária. Professor e orientador no Programa de Pós-Graduação em Ambiente e Desenvolvimento do Centro Universitário UNIVATES e professor no Centro Universitário UNIVATES. Email: okonrad@univates.br.

3 Doutora em Informática na Educação. Coorientadora no Programa de Pós-Graduação em Ambiente e Desenvolvimento do Centro Universitário UNIVATES e professora no Centro Universitário UNIVATES. Email: mrehfeld@univates.br. 
for teachers; (b) the school management as a trigger for the participative and democratic process within schools promotes the possibility of developing the consciousness of the school community characters.

Keywords: Environmental Education. School Management. Perspectives and Education.

\section{INTRODUÇÃO}

Este artigo é um recorte da pesquisa sobre as concepçóes apresentadas por diretores escolares no que tange à gestấo educacional e à educação ambiental em escolas estaduais do Rio Grande do Sul. A pesquisa tem como objetivo geral: investigar como os diretores das escolas estaduais pertencentes a $3^{\text {a }}$ Coordenadoria Regional de Educação/RS compreendem o papel da gestão escolar e a educação ambiental nas escolas de educação básica, de modo a indicar possíveis elementos para ressignificar o papel da gestão escolar e o ensino da educação ambiental.

Pesquisar sobre a gestão escolar e a educação ambiental é um desafio constante, pois são áreas que recebem reiterada atenção e são muitos os autores que dedicam suas obras a discutir essas temáticas. Esses assuntos trazem na sua essência várias visóes e reflexôes. Analisando a situação ambiental atual e levando em consideração as mudanças ocorridas na nossa sociedade, percebe-se a carência de propostas educacionais alternativas e inovadoras para acompanhar ou questionar essas transformaçóes.

Partindo de análises que buscam contribuir para o desenvolvimento de um ensino com mais qualidade, as pesquisas na área educacional pretendem problematizar as questóes que envolvem o conhecimento profissional dos docentes que atuam na educação básica, a reflexão sobre essa atuação, bem como enfrentar as situações de conflito e incertezas. As pesquisas também revelam que a forma como os docentes desenvolvem sua prática influencia na maneira como os estudantes aprendem. Portanto, faz-se necessário compreender como os estudantes desenvolvem sua própria aprendizagem para poder assessorar os docentes na compreensão de sua própria aprendizagem e, por conseguinte, melhorar a aprendizagem de seus estudantes, ou seja buscar a ação-reflexão-ação como um processo contínuo (FREIRE, 1995).

Ao considerar a necessidade de ressignificar a formação continuada de docentes, os processos de ensino e de aprendizagem precisam ser explorados e refletidos para que os professores possam desenvolver suas práticas pedagógicas comprometidas com uma visão crítica sobre um mundo complexo e em transformação. Sob essa perspectiva de um mundo em transformação, exige-se dos docentes uma percepção ampla e ética do significado das relaçōes entre o ser humano e o ambiente.

As pesquisas visam promover a contribuição para as mudanças necessárias nas relações entre os seres humanos e o ambiente e para o desenvolvimento de atitudes significativas, comprometidas com a realidade em que os estudantes da educação básica, estão inseridos. No entanto, essas contribuiçóes precisam ser compreendidas e discutidas no universo escolar, pelos docentes e pela gestão escolar, para que essas atitudes se concretizem nas habilidades desenvolvidas pelos estudantes. 


\section{FUNDAMENTOS TEÓRICOS}

\subsection{Educação ambiental - crítica na construçáo da cidadania}

As preocupações com as questóes ambientais vêm sendo discutidas, enfaticamente, desde o século XVIII, após a primeira Revolução Industrial. Carvalho (2010, p. 54) descreve que nos séculos XVI e XVII houve a busca da "afirmação humana pelo domínio da natureza no contexto social [...]", resultando em uma "nova ordem burguesa e mercantil". A indústria, nesse período, cresce trazendo a possibilidade de progresso, porém atrelada à degradação ambiental, a partir da utilização do carvão como combustível.

As consequências, na época, da utilização do carvão como combustível e o trabalho nas fábricas são destacadas por Carvalho (2010) como as grandes transformações sociais e ambientais que trazem a deterioração do ambiente urbano, a partir da migração de pessoas do campo para as cidades, resultando no aumento da população nos espaços urbanos, nas quais não havia coleta de lixo nem saneamento básico.

No Brasil, as questóes ambientais surgem a partir do movimento ecológico, que compunha uma área da Biologia. Tristão e Jacobi (2010, p. 14) explanam que a educação ambiental "emergiu como decorrência da visibilidade e repercussão das açóes promovidas pelo movimento ecológico, e foi gradualmente assimilada como um campo da educação geral, e mais recentemente da pesquisa em educação”. As questões ambientais passam a ser foco de pesquisas nas mais diversas áreas das ciências sociais e humanas, das ciências naturais e da terra, pois recebem atenção de jovens profissionais e estudantes que vislumbram projetos de transformaçôes sociais.

A partir disso, a educação ambiental vem sendo vista como um processo integral, político, pedagógico e social, estando ligada ao contexto histórico-cultural que sofreu influência dos valores perpetuados pelo ecologismo. Tristão e Jacobi (2010, p. 15) descrevem que a educação ambiental teve sua construção agregada aos preceitos do movimento do ecologismo, que teve "um importante papel na formulação e implementação de políticas públicas e na promoção de estratégias para inserir o conceito de sustentabilidade ao de desenvolvimento".

A implementação de políticas públicas também acontece na dimensão educacional. Conforme Lacerda (2010, p. 38), as "reflexóes sobre a transição paradigmática, as formas de globalização e a sustentabilidade são importantes para a compreensão do surgimento e difusão da educação ambiental, como dimensão educativa de alguns desses processos". Lacerda (2010) destaca, ainda, que a trajetória da educação ambiental, propagada a partir da realização das Conferências Mundiais de Tbilisi (1977) e da Rio/92 e concretizada em suas continuaçóes locais, surge de uma entrelaçada "rede de saberes, que compreendem questóes históricas, sociais, culturais, políticas, filosóficas, discursivas, educacionais, ambientais, entre outras [...]", ficando difícil ser trabalhada na educação por apenas uma disciplina ou em grupo de disciplinas. Assim, surgem as dimensões: interdisciplinar, transdisciplinar e multidisciplinar da educação ambiental.

A educação ambiental encontra-se no centro das reflexóes da sociedade, pois traz questionamentos que envolvem e influenciam a forma com que os sujeitos se relacionam 
entre si e com o ambiente. Esses questionamentos são pertinentes e envolvem todos os segmentos sociais, exigindo uma postura crítica e cidadá diante dos problemas planetários. Sato e Carvalho (2005, p. 12) destacam que "a educação ambiental pode ser uma preciosa oportunidade na construção de novas formas de ser, pensar e conhecer que constituem um novo campo de possibilidades de saber".

A educação básica, nesse contexto, tem a função de desenvolver essa postura crítica e cidadâ, pois opera com a formaçáo de sujeitos atuantes na sociedade. Essa formação deve ser combinada com a prática docente mais comprometida com o "aprender a aprender" (DELORS, 2000), com metodologias inovadoras e com as mudanças de paradigmas que requerem uma "expansão da percepção e da maneira de pensar também os valores" (CAPRA, 2006, p. 27).

Para Carvalho (2005), a educação ambiental precisa considerar de forma séria a noçáo de aprendizagem entendida como processo de mudanças cognitivas, sociais e afetivas dos sujeitos, grupos e instituiçóes para sair do lugar marginalizado que ocupa na escola. Seu desafio, destaca ainda a autora, é construir uma sensibilidade e uma leitura crítica dos problemas ambientais. Brown (apud CAPRA, 2006, p. 24) alerta que "uma sociedade sustentável é aquela que satisfaz suas necessidades sem diminuir as perspectivas das gerações futuras".

Essa preocupação com um novo currículo para a educação básica no Brasil aparece nos Parâmetros Curriculares Nacionais (PCN) para o Ensino Fundamental e o Ensino Médio, que fazem menção ao currículo Ciência-Tecnologia-Sociedade (CTS). A relaçáo dessa forma de abordar o currículo é uma das preocupações trazidas por Gadotti (2000, p. 236) quando alerta sobre os conteúdos curriculares que precisam ser "significativos para o aluno e só serão significativos para ele se esses conteúdos também forem significativos para a saúde do planeta num contexto mais amplo".

González-Gaudiano (2005, p. 119) auxilia na proposta de pensar o currículo escolar como um diálogo entre as disciplinas que deve desencadear a busca "de novos sentidos do conhecimento que as disciplinas individuais por si mesmas não estavam em condiçóes de proporcionar". No entanto, essa mudança de olhar sobre a proposta curricular escolar vai exigir uma formaçáo continuada dos docentes, pois a lógica, ainda, desenvolvida nas escolas parte da visão do trabalho por disciplinas individualizadas no seu tempo e espaço.

Para Leff (2006, p. 374), a crise ambiental foi "associada ao fracionamento do conhecimento", trazendo como consequência a necessidade da compreensão da complexidade do mundo atual. O autor destaca que a "interdisciplinaridade e a teoria de sistemas emergem como dispositivos metodológicos para a constituição de um saber holístico", que podem contribuir para a reintegração das partes de um conhecimento, contribuindo para a ressignificação ou religação da educação ambiental nas esferas escolares.

Rosa (2009, p. 47) destaca que a formação docente necessita "desenvolver as reflexóes sobre a dimensão ambiental no currículo escolar, na escolha de metodologias adequadas para despertar a consciência planetária e contribuir na gestão das políticas públicas”. Portanto, a função dos profissionais da educação deveria ser a de contribuir para uma sociedade mais crítica e questionadora. Nesse aspecto, o docente se transforma em um sujeito ativo e náo 
apenas transmissor de informações que para o estudante, muitas vezes, não têm 'sentido'. Para Gutiérrez e Prado (2002, p. 63), a “educação é um processo de elaboração de sentidos”.

\subsection{Gestáo democrática e participativa}

As discussôes acerca da gestão escolar passam a entrar no cenário educacional como um termo adotado pela legislação educacional a partir da promulgação da Constituição Federal do Brasil de 1988, que traz esse termo com a ideia de gestão democrática para o ensino público e de autonomia administrativa. Essa ideia se repete, nos anos subsequentes, por meio da promulgação da Lei de Diretrizes e Bases da Educação Nacional (LDBEN) no 9.394 em 1996, que retoma a gestão democrática como a forma que passa a vigorar ao administrar as instituiçóes de ensino.

No artigo 14 da LDBEN no 9.394/96 (BRASIL, 2016, p. 6), está a descrição sobre como as instituiçóes de ensino devem ser administradas:

Os sistemas de ensino definirão as normas da gestão democrática do ensino público na
educação básica, de acordo com as suas peculiaridades e conforme os seguintes princípios: I
- participação dos profissionais da educação na elaboração do projeto pedagógico da escola;
II - participação das comunidades escolar e local em conselhos escolares ou equivalentes;
[...].

A partir dessas proposiçóes legais surgem diversas políticas públicas para determinar como a gestão democrática deve acontecer, pois as instituiçôes de ensino públicas passam a administrar as verbas enviadas pelos governos, tanto federal como estadual. $\mathrm{O}$ artigo 15 da LDBEN no 9.394/96 descreve a forma como esse processo deve acontecer: "os sistemas de ensino assegurarão às unidades escolares públicas de educação básica que os integram progressivos graus de autonomia pedagógica e administrativa e de gestão financeira, [...]" (BRASIL, 2016, p. 6). No entanto, essa proposta de gestão está mais vinculada às questóes da escola. Lück (2006, p. 25) apresenta uma separação entre gestão educacional e gestão escolar, ou seja, quando se fala sobre "gestão educacional, faz-se referência à gestão em âmbito macro, a partir dos órgãos superiores dos sistemas de ensino, e em âmbito micro, a partir das escolas".

Tomando como base as duas legislações - Constituição Federal /88 e a LDBEN no 9.394/96, é possível perceber uma mudança significativa no papel da gestão escolar e dos sujeitos que compóem essa gestão - direção, vice-direção, coordenação pedagógica ou supervisão escolar e os demais membros. Essas reformas visavam à descentralização como forma de transferência de responsabilidade, tanto da gestão como de execução dos serviços educativos da União para os Estados e municípios. Essas mudanças políticas estavam em discussão desde a década de 1980, priorizadas pela ideia de igualdade de acesso à educação.

A gestão escolar está atrelada às políticas da educação voltadas à gestão democrática e participativa da educação e à qualidade do ensino no Brasil. A dimensão que trata da gestão democrática da educação apresenta vários questionamentos na forma como ela está sendo desenvolvida. Cóssio, (2006, p. 30-31) destaca que "democratizar a gestão da educação numa perspectiva social [...] requer, fundamentalmente, que a sociedade possa participar 
no processo de formulação e avaliação da política de educação e na fiscalização de sua execução". Assim, a participação do cidadão enquanto sujeito atuante nos aspectos que abordam a educação está entrelaçada à prática administrativa e pedagógica desenvolvida nas escolas.

Para Mello e Cóssio (2006, p. 43), a "participação coletiva constitui-se em instrumento básico de uma gestão democrática e pressupóe a disposição para o debate, reflexão, problematização, estudo, aplicação, avaliação e reformulação em função das próprias mudanças sociais e políticas”. Essa participação necessita do exercício de um sujeito ativo, aberto e disposto ao diálogo que, no coletivo, possa expor suas opinióes e ouvir as opinióes dos outros. Segundo Alves (2010, p. 31), a comunidade escolar deve ter ciência que, muitas vezes, "as decisóes tomadas por especialistas, gestores ou pelos que ocupam posições de chefia [...] repercutem sobre as coletividades".

Considerando a necessidade da participação como processo de construção de um coletivo mais justo e cidadão, a gestão da educação tem um papel importante nesse processo, em que as políticas de gestão descritas na Constituição Federal do Brasil/1988 e na LDBEN $\mathrm{n}^{\circ}$ 9.394/1996 fazem referências à gestão escolar democrática e participativa (FERREIRA, 2008), responsável pela mediação e construção coletiva do Projeto Político e Pedagógico das escolas e a relação com a formação continuada dos profissionais da educação. Esse documento da escola passa a ter a função de mobilizar a comunidade para refletir sobre a realidade escolar e a busca de possibilidades de mudanças nessa realidade, ou seja, a "tensão entre repetição e inovação" (OLIVEIRA, et al., 2012, p. 41).

A gestão escolar deveria desempenhar, segundo Paro (2007, p. 50), a função de "mediadora entre a administração escolar e o pedagógico", desencadeando a possibilidade de reflexão sobre esse pedagógico e da inclusão dos pais e da comunidade escolar nessa discussão. Paro (2007) descreve, ainda, o papel educador da escola que se estende aos pais dos estudantes, que também são cidadãos e podem se beneficiar com essa ação escolar, incentivando a participação.

Cury (2012, p. 17) destaca que atualmente os cidadãos almejam conhecer os "processos de decisão por meio da transparência dos atos [...] e exercer uma fiscalização do exercício do poder”, ou seja, um cidadão ativo. O autor destaca, também, que a gestão democrática como um princípio da educação brasileira se torna uma das formas de capacitar a comunidade escolar para exercer sua cidadania, para participar da sociedade "como profissionais compromissados [...]" (CURY, 2012, p. 18).

Ao destacar a importância de formar um cidadão ativo, que questione e que atue na realidade, pressupóe-se a convicção de que a mudança é possível (FREIRE, 2010). Assim, Freire (2010, p 77) também destaca que "nos tornamos capazes de intervir na realidade, tarefa incomparavelmente mais complexa e geradora de novos saberes do que simplesmente a de nos adaptar a ela”. Para que essa situação aconteça, é necessária uma mudança na forma de desenvolver o trabalho da gestão escolar.

Freire $(2010,2000,1995$ a, 1995b) destaca em suas reflexôes que a relação dialógica do ser humano é um exercício e, como tal, precisa ser efetuada e promovida no coletivo. Nesse aspecto, vale destacar a importância do sujeito se "abrir ao mundo e aos outros, 
inaugurando com seu gesto a relação dialógica em que se confirma como inquietação e curiosidade" (FREIRE, 2010, p. 136).

\section{PROCEDIMENTOS METODOLÓGICOS}

A pesquisa seguiu os contornos de abordagem quali-quantitativa, a qual que essa possibilita utilizar procedimentos qualitativos e quantitativos por meio da integração dos dados (DEMO, 2014; CHEMIN, 2012; DIEHL; TATIM, 2004; MARCONI; LAKATOS, 2010). A dimensão quantitativa da pesquisa está relacionada às "condiçóes objetivas historicamente dadas" (DEMO, 2014, p. 95), que apresentam as questóes de identificação dos pesquisados, considerando: gênero, idade, formação, tempo de atuação na gestão, entre outros. A dimensão qualitativa busca delinear a complexidade de determinado problema, procurando compreender e interpretar os processos vividos por grupos sociais (DIEHL; TATIM, 2004; DIAS; SILVA, 2010; FIGUEIREDO; SOUZA, 2011). Para tanto, esta pesquisa se caracteriza como descritiva e exploratória, sendo as mais indicadas nas pesquisas sociais.

As pesquisas descritivas têm como principal objetivo a descrição das características de determinada população ou fenômeno, utilizando técnicas padronizadas de coleta de dados, como o questionário (CHEMIN, 2012). Esta pesquisa é exploratória porque visa a proporcionar uma "visão geral, de tipo aproximativo, acerca de determinado fato" (GIL, 2012, p. 27-28) e envolve revisão de literatura. O estudo exploratório também analisa a documentação como forma primária de coleta de dados.

Esta pesquisa ainda se classifica como bibliográfica e de levantamento ou survey. A pesquisa bibliográfica se caracteriza por realizar a revisão teórica, tendo como propósito fornecer fundamentação teórica ao trabalho, assim como a identificação do estágio atual do conhecimento referente ao tema. A pesquisa de levantamento ou survey visa à interrogação direta das pessoas cujo comportamento se deseja conhecer, a solicitação de informaçóes a um grupo significativo de pessoas, mediante análise quantitativa (CHEMIN, 2012; GIL, 2010; DIEHL;TATIM, 2004; FIGUEIREDO; SOUZA, 2011).

Este trabalho foi desenvolvido a partir de respostas fornecidas pelos diretores das escolas estaduais pertencentes à $3^{\text {a }}$ Coordenadoria Regional de Educação, localizada no Vale do Taquari, região composta por 37 municípios no Estado do Rio Grande do Sul. A $3^{\text {a }}$ CRE possui sob sua responsabilidade 92 escolas estaduais, constando neste trabalho as informaçóes de 52 escolas, representando 56,5\% das escolas estaduais do Vale do Taquari.

$\mathrm{O}$ instrumento de pesquisa utilizado foi um questionário elaborado pela primeira autora da pesquisa. $\mathrm{O}$ questionário aplicado foi o instrumento que melhor se enquadrou para realizar a coleta das informaçóes, que possibilitaram conhecer o contexto da gestão escolar na $3^{\text {a }} \mathrm{CRE} / \mathrm{RS}$. Esse instrumento de coleta de dados é definido por um conjunto de questóes que são respondidas por escrito pelo pesquisado (GIL, 2012; MARCONI; LAKATOS, 2010; FIGUEIREDO; SOUZA, 2010).

O questionário foi constituído por questóes fechadas e abertas, sendo organizadas algumas das questóes fechadas utilizando a escala Likert. Essa escala se baseia na de Thurstone, que, segundo Gil (2012, p. 142), “constitui a primeira experiência de mensuração de atitudes 
com base numa escala de intervalos". A utilização da escala Likert possibilitou identificar a compreensão que os diretores das escolas estaduais têm sobre a educação ambiental e reconhecer a relevância que os gestores das escolas estaduais atribuem à educação ambiental.

Os questionários foram enviados por e-mail via instrumento organizado no Google drive. Os dados coletados foram tratados de forma anônima e confidencial, preservando a identidade dos respondentes. Para resguardar suas identidades, os diretores entrevistados estão identificados pela letra "D", acompanhada por um numeral arábico, por exemplo: D1, D2, D3 e assim sucessivamente até D52.

As informaçōes trazidas pelos questionários foram analisadas seguindo a metodologia de "análise de conteúdo", que é conceituada por Bardin (2012, p. 42) como:

\begin{abstract}
um conjunto de técnicas de análise das comunicaçôes, visando obter, por procedimentos, sistemáticos e objetivos de descrição do conteúdo das mensagens, indicadores [...] que permitam a inferência de conhecimentos relativos a condiçôes de produção/reprodução [...] destas mensagens.
\end{abstract}

A descrição e a análise dos conteúdos das mensagens foram observadas, procurando ser fiel aos dados coletados e à essência do tema em análise, além de desvelar os fatores interferentes no fenômeno. Assim, as informaçōes foram divididas em categorias para a análise, configurando-se em evidência no enfoque da compreensão do papel da gestáo escolar e da educação ambiental, visando a um ensino mais qualificado.

\title{
4 ANÁLISE DOS DADOS
}

Quanto ao aspecto da identificação dos participantes da pesquisa, os respondentes estão divididos em $90,4 \%$ do sexo feminino e $9,6 \%$ do sexo masculino, correspondendo a 47 mulheres e 5 homens, totalizando 52 pessoas que ocupam o cargo de diretores das escolas estaduais pertencentes à $3^{\text {a }} \mathrm{CRE}$, localizadas no Vale do Taquari/ RS. Considerando que nessa regiāo se encontra o total de 92 escolas estaduais, o valor de 52 questionários respondidos representa $56,5 \%$ dos diretores das escolas estaduais do Vale do Taquari.

Em relação à faixa etária dos respondentes, é possível perceber que mais de $80 \%$ dos diretores têm mais de 40 anos de idade, ou seja, esse é um grupo de profissionais que possui uma experiência de vida significativa. Quarenta e quatro vírgula dois por cento têm entre 41 e 50 anos, abrangendo a maioria. Ao refletir sobre a experiência de vida desse grupo, podese observar que essas pessoas vivenciaram situaçóes com diversas mudanças econômicas e sociais no âmbito do desenvolvimento do país, o que é relevante ao pensar na educação de forma geral.

No Gráfico 1 constam as informaçóes relacionadas à formação em nível de graduação dos diretores participantes da pesquisa. 
Gráfico 1 - Formação em Graduação

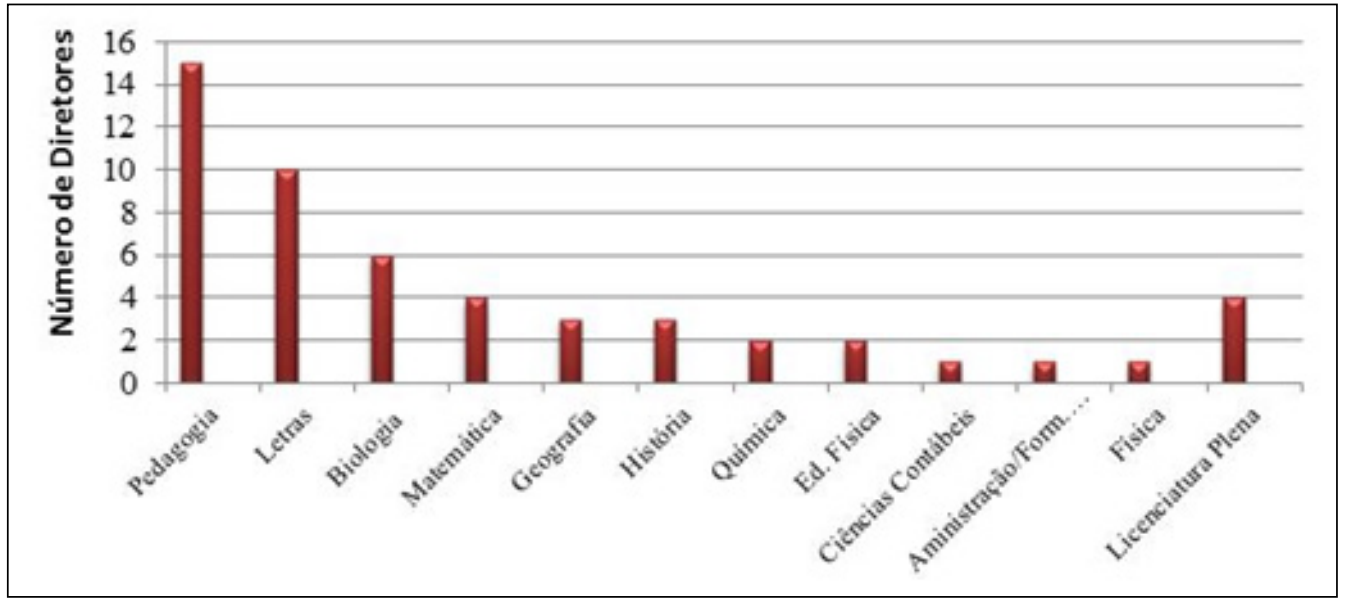

Fonte: dos Pesquisadores (2016).

Nesse grupo, ainda tem-se apenas 28,8\% com formação em Pedagogia, sendo os demais, aproximadamente $71,2 \%$, são formados em outras áreas, sendo que desse total, apenas $59,7 \%$ declararam formação em licenciatura. Considerando que a LDBEN no 9.394/96 cita no artigo 64 que: “a formação de profissionais de educação para administração, planejamento, inspeção, supervisão e orientação educacional para a Educação Básica, será feita em cursos de graduação em pedagogia [...]” (BRASIL, 2016, p. 27). O artigo 64 traz uma informação que, em muitos casos, não está de acordo com o contexto educacional atual.

No Gráfico 2 contam as informações relacionadas à formação em nível de pósgraduação especialização (lato sensu) dos diretores participantes da pesquisa. 
Gráfico 2 - Formação em Pós-Graduação Especialização (lato sensu)

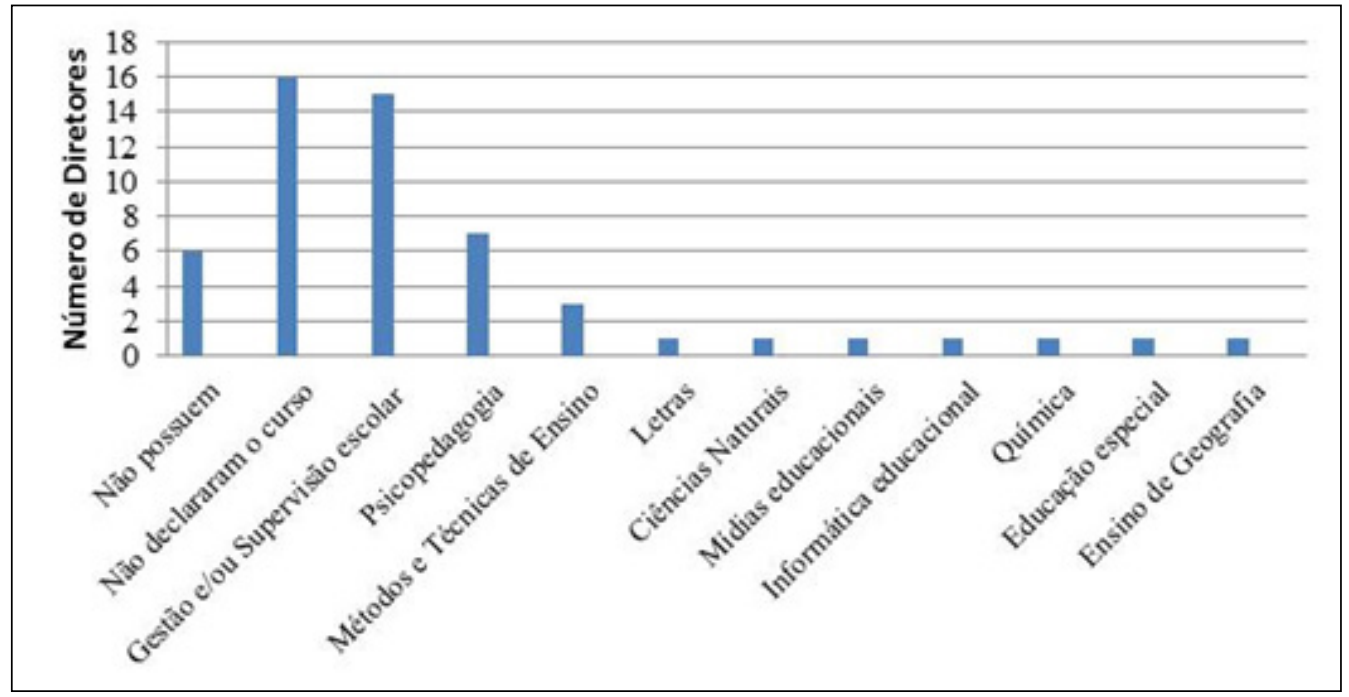

Fonte: dos Pesquisadores (2016).

Dos 52 respondentes, foi possível verificar que 11,5\% deles não possuem formação em nível de pós-graduação, porém esse é um percentual baixo comparado com os $88,5 \%$ que possuem formação lato sensu. As formaçóes indicadas pelos respondentes são as mais variadas possíveis, e apenas 32,6\% dos 46 diretores têm especialização. De acordo com Schneckenberg (2009, p. 116), a formação do diretor visa a "uma característica de atuação que pretende organizar, mobilizar e articular condições materiais e humanas necessárias para efetivar o avanço dos processos sócio-político-educacionais da instituição escolar”.

Tabela 1 - Tempo de Atuação (anos) na Docência

\begin{tabular}{cc}
\hline Anos de atuaçáo & No de respondentes e \% \\
\hline $1-15$ & $17(33 \%)$ \\
$16-30$ & $26(50 \%)$ \\
$31-45$ & $08(15,1 \%)$ \\
Não declarou & $01(1,9)$ \\
\hline Total & $\mathbf{5 2}$ \\
\hline
\end{tabular}

Fonte: dos Pesquisadores (2016).

Os anos de atuação informados pelos respondentes mostram que a maioria, ou seja, 65,1\% do grupo apresenta mais de 16 anos de experiência na docência na educação básica. Isso demonstra que esse grupo tem grande experiência na função da docência, no entanto, a função de gestão traz a necessidade de transformação desse sujeito de docente para diretor. Gonçalves (2010, p. 82) destaca que é preciso que "o diretor da escola se transforme no 
gestor escolar, consciente de seu papel mobilizador de esforços e recursos, em torno não só da aprendizagem dos alunos, mas da autonomia e da democratização das práticas escolares".

Ao constatar o tempo de atuação na gestão escolar, por um lado, foi possível perceber que os gestores possuem experiências que variam de menos de 1 ano até 30 anos como gestores escolares. Isso nos mostra que existe um grande disparidade no grupo. A organizaçáo dessas informações consta na Tabela 3.

Tabela 2 - Tempo de Atuação na Direção Escolar

\begin{tabular}{cc}
\hline Anos de atuaçáo & No de respondentes e \% \\
\hline $0-10$ & $39(75 \%)$ \\
$11-20$ & $11(21,2 \%)$ \\
$21-30$ & $02(3,8 \%)$ \\
\hline Total & $\mathbf{5 2}$ \\
\hline
\end{tabular}

Fonte: dos pesquisadores (2016).

Por outro lado, o tempo de atuação na direção escolar mostra que $75 \%$ dos respondentes possuem até 10 anos de experiência. Cabe salientar que a função de direção de escola pode ser vista por uma complexidade de enfoques, demonstrando um papel transitório entre a docência e a gestão. Conforme Junquilho, Almeida e Silva (2012, p. 348) "o fato de os diretores escolares eleitos ou, [...], indicados pelos órgãos centrais, serem docentes que assumem esse 'lugar' [...] por um tempo determinado e sofrem o dilema de estarem diretores de seu ambiente de trabalho [...]".

\subsection{Acompanhamento do trabalho pedagógico:}

A compreensão do papel da gestáo escolar em relação ao acompanhamento do trabalho pedagógico apresentou diversas visóes nas respostas dos questionários. As respostas foram organizadas em quatro aspectos principais nos quais constam as declaraçóes dos diretores. $\mathrm{O}$ primeiro diz respeito aos recursos financeiros e humanos, ressaltando que são difíceis de acompanhar e podem comprometer as questôes pedagógicas, ou seja, demonstra uma interdependência entre estas áreas: financeiro e pedagógico. Considerando essa relação entre recursos financeiros e pedagógicos temos as seguintes declaraçóes:

[...] considero a administração dos recursos econômicos e humanos a mais difícil e que acabam comprometendo [...] o planejamento pedagógico [...] (D5). A gestáo está a serviço da articulação entre pedagógico e o político [...] devem dar condiçôes para que o papel pedagógico da escola: ensinar, humanizar e protagonizar seja vivenciado amplamente (D20). O gestor escolar deve [...] proporcionar condiçóes para que o trabalho pedagógico seja realizado da melhor forma possível (D25).

A preocupação com os recursos financeiros e humanos perpassa as inquietaçóes dos diretores. Conforme Silva (2011, p. 22), essa visão persiste porque existe uma cultura em que o "poder de decisão segue basicamente do diretor, segundo o princípio de 
ordenação burocrático, uma vez que suas atribuiçóes, de modo geral, priorizam as questóes administrativas e burocráticas, em detrimento das pedagógicas [...]”. Essa é uma articulação complexa que exige do diretor uma atitude mais proativa.

O segundo aspecto constatado nas colocaçóes dos diretores está vinculado à separação das funções pedagógicas e administrativas, que são desempenhadas por diferentes profissionais. Assim, pode-se observar essa separação nos seguintes depoimentos:

A coordenaçáo pedagógica cuida dessa parte e trabalhamos em equipe, um auxilia o outro (D30). [...] apesar das poucas pessoas que temos para atuar junto ao trabalho pedagógico as pessoas se desdobram e atendem várias funções ao mesmo tempo [...] (D31). O apoio dos profissionais responsáveis pelo pedagógico e a supervisão escolar é muito importante para manter a qualidade do ensino e aprendizagem (D33). O acompanhamento pedagógico dos docentes é feito em conjunto entre direção e coordenação pedagógica, pois acreditamos ser importante que haja esta cumplicidade e comprometimento de todos (D19). O diretor sempre deve acompanhar o trabalho dos docentes com a finalidade de satisfazer a comunidade escolar frente às suas expectativas de aprendizagem. $\mathrm{O}$ gestor percebe quando algo não está bem e intervém de forma a auxiliar os professores encontrando melhores formas de resolver os problemas pedagógicos, acionando a coordenaçáo pedagógica da escola, através de um trabalho em equipe (D26).

Em relação ao trabalho desenvolvido em conjunto por diferentes profissionais, nos depoimentos dos diretores essa parceria fica evidente. Os aspectos pedagógicos estão sob a responsabilidade da coordenação pedagógica, em maior proporção. Paro (2007, p. 20) destaca que o "papel estratégico da estrutura didática e administrativa na realização das funçôes da escola” é um aspecto imprescindível para se obter qualidade na educação.

O terceiro aspecto abordado trata dos adjetivos ou açóes diretamente vinculadas ao papel do gestor, demonstrando a importância designada a essa função. Essa importância fica evidente nos seguintes depoimentos:

Quanto ao acompanhamento pedagógico é significativo diante do aprendizado dos alunos. (D2). O papel da gestão escolar é estar em constante acompanhamento com as atividades pedagógicas desenvolvidas na escola [...] (D16). Compreendo que o gestor tem o papel de mediador entre os segmentos, [...] oferecendo uma educaçáo de qualidade (D21). No acompanhamento do trabalho pedagógico dos docentes a gestão escolar precisa mobilizar e estimular a todos os profissionais da educação de modo a comprometê-los com a construçáo do conhecimento e da aprendizagem orientada para a cidadania competente (D37). O trabalho docente necessita um olhar constante e vigilante (D42). Uma boa gestão escolar [...] desenvolve o acompanhamento do trabalho pedagógico dos docentes [...] (D42). A observaçáo e comparaçáo dos planos de estudos e as aulas ministradas pelos professores é de suma importância para que exista, em nível de Estado, uma forma idêntica de conhecimento e aprendizagem (D49). Deve orientar, conduzir e avaliar os resultados alcançados, juntamente com supervisora, para que a aprendizagem aconteça (D32). O gestor [...] deve estar atento a todas as situaçóes pedagógicas desenvolvidas pela escola [...] (D7). [...] precisa ser incentivadora para a busca constante de aprimoramento de sua equipe [...] (D43). O acompanhamento pedagógico é fundamental e necessário fazê-lo em conjunto com os professores e funcionários para que possamos estimular a criatividade $\mathrm{e}$ a autonomia do corpo discente para a educação integral (D41) (Grifo dos pesquisadores). 
Nos depoimentos dos diretores sobre a importância do papel do diretor no trabalho didático-pedagógico desenvolvido na escola, destacam-se expressóes como: constante, mobilizar, estimular, compreendê-los, orientar, conduzir, avaliar, entre outras, demonstrando que no olhar dos diretores suas funçóes são importantes. Para Vieira, Almeida e Alonso (2003), para que o diretor promova mudanças estruturais, precisa fazer parcerias, viabilizar a participação dos alunos nas decisóes, estimular a aprendizagem ativa, propiciar o desenvolvimento profissional dos professores, favorecer a participação da comunidade, entre outros.

\subsection{Formaçáo continuada dos docentes da escola:}

O papel do diretor na gestáo escolar traz inúmeras incumbências que dependem de seu encaminhamento e organizaçáo. A formaçáo continuada dos docentes que atuam nas escolas também faz parte da função do diretor. Os depoimentos dos diretores mostram uma preocupação com a formação continuada de docentes, no entanto apenas 18 citaçóes diretas foram realizadas nesse item, que corresponde a $34,6 \%$ do total de diretores pesquisados.

Considerando os depoimentos dos diretores D24 e D39, pode-se perceber a preocupação com a formação continuada:

o papel do gestor com a formação continuada é direta e constante. Ele deve ser um identificador de situaçóes que carecem de mais estudo. Serve como elo (D24)". [...] oferecer a possibilidade de formação continuada é uma grande responsabilidade que só tem a acrescentar para o corpo docente, uma vez que através dela que se reflete a essência do trabalho a ser desenvolvido no ambiente escolar (D39).

A preocupação com a formaçáo continuada de docentes faz parte das pesquisas de Oliveira (2010, p. 56), que convoca para uma formação focada no empreendedorismo como "um investimento no capital humano". Guilherme e Fischer (2011, p. 60) destacam: "aperfeiçoamento da prática pedagógica dos sujeitos envolvidos se processa com base em valores educativos e [...] os espaços destinados ao processo de ensinar e de aprender são como complexos sistemas de comunicação em que se intercambiam [...], diferentes formas de pensar, de expressar, de sentir e de atuar".

Os diretores respondentes salientam a relação entre a importância da formação continuada dos docentes e o trabalho pedagógico realizado em sala de aula como forma de incentivo e de possibilidade de atualização, visando à diversidade dos estudantes. Essa relação fica evidente nos seguintes depoimentos:

Trabalho que deve ser sempre atualizado e dentro das perspectivas da realidade escolar e comunidade que a escola está inserida (D33). A formaçâo deve ser continuada para darmos conta da diversidade que os alunos apresentam (D2). A formaçáo continuada dos docentes é necessária para a atualização e aperfeiçoamento das áreas do conhecimento. O papel da gestão é promover, acompanhar e participar da formação continuada, pois só assim nossos alunos serão bem atendidos e orientados na sala de aula (D37). A formação continuada é muito importante, pois injeta inovação e motivaçáo à prática educativa (D26). Formação continuada é tudo de bom que pode haver para que a instituiçấo escolar se atualize e avance para buscar cada vez mais melhorar os índices de aprovação e desenvolvimento pedagógico (D41). 
A forma de organização dessa formação continuada fica a cargo da equipe diretiva da escola em parceria com a mantenedora (CRE, Secretaria Estadual de Educação) e com outras instituiçóes que possam auxiliar nesse trabalho, como por exemplo, universidades. Porém, consta a preocupação com a questão econômica, com a obtenção de recursos para a realização dessa atividade. Para Santos $(2010$, p. 241), a tarefa da gestão em relação a formação dos docentes precisa ser retomada, pois revela "a necessidade de repensar a formação de professores como profissionais críticos e reflexivos, com uma postura interdisciplinar e construtivista, capazes de compreender as relaçóes entre trabalho pedagógico e exercício da cidadania”.

No que diz respeito à formação de professores, a $3^{a}$ CRE disponibilizou aos pesquisadores seus Relatórios das Atividades de Diversidade de 2011, 2012 e 2013, sob a responsabilidade do Núcleo Diversidade, nessa Coordenadoria. No Relatório de 2011, apresenta-se o oferecimento, aos docentes da rede estadual, de diversas atividades de formação em diversidade e educação ambiental, como, por exemplo, o Curso de Formação em Multiplicadores de Educação Ambiental que se "identificam com os temas relacionados ao Meio Ambiente e que possam contribuir e construir uma rede de comunicação e atividades nesta área" (RAD, 2011, p. 7), em parceria com uma universidade.

No Relatório das Atividades de Diversidade de 2012, foi oferecida a Formaçáo da Agenda 21 e Com-Vida para 40 professores da rede estadual. Essa formação integrou as ações da Pós-Conferência Infanto-Juvenil para o Meio Ambiente, com duração de oito horas, sendo seu objetivo geral "fortalecer as ações de Educação Ambiental e gestão Ambiental com a implantação da Agenda 21 escolar" (RAD, 2012, p. 10). Essa proposta visava a oportunizar aos professores a ampliaçáo de conhecimentos, o debate e a vivência de atividades relacionadas à temática ambiental, por meio de oficinas e palestras.

No ano de 2012, também ocorreu o Curso de Formaçáo Continuada: Construindo Cidadania a partir do Diálogo na Diversidade, com duração de 40 horas, sendo seus objetivos:

\footnotetext{
Qualificar o educador em relação à diversidade, tendo como alvo as relações de convivência através de uma atitude de respeito às diferentes culturas relacionadas ao contexto escolar e seu entorno; formar um espírito crítico sobre as manifestações religiosas na atualidade e sua relação com a filosofia, a política, a economia e a psicologia, na perspectiva da cidadania; desenvolver uma atitude de respeito, diálogo e cuidado para com a diversidade; dialogar e refletir sobre o currículo do Ensino Religioso, articulando-o com as demais áreas do conhecimento (interdisciplinaridade); desenvolver competências, visando à atuaçáo do educador em sala de aula, considerando o contexto escolar e a parte diversificada do currículo do ensino médio (RAD, 2012, p. 15).
}

Outra atividade promovida pela $3^{a}$ CRE, no ano de 2012, foi o Encontro de Formação - Educação, Diversidade e Cidadania, que teve como objetivo geral "promover espaços de reflexão e aprofundamento em vistas de uma cultura de respeito à pluralidade e a diversidade" (RAD, 2012, p. 16). Esse encontro teve duraçáo de oito horas e contou com palestras e painéis. 
No Relatório das Atividades de Diversidade de 2013, relata-se a Formação sobre Prevenção e Promoçáo da Vida - Plantas medicinais, indicada a professores e funcionários das escolas estaduais, sendo indicados por escola um professor e uma merendeira, totalizando 180 pessoas. O objetivo geral dessa formação foi "resgatar saberes sobre plantas medicinais e realizar pesquisas investigativas com estudos e aprofundamentos" (RAD, 2013, p. 3). Essa formação contou com carga horária de oito horas, e teve como metodologia de trabalho palestras, oficinas práticas com orientaçóes e acompanhamentos para o cultivo de plantas.

Os depoimentos a seguir mostram como essa organizaçáo e parceria ocorrem:

\begin{abstract}
Sabemos que a formação continuada é importante e [...] quando possível e há recurso, é feita na escola, onde professores e funcionários participam. Além disso, sempre são divulgados cursos, palestras que vêm pela CRE, das universidades (D19). A formação continuada é realizada, normalmente em dois momentos anuais, através das formaçôes pedagógicas [...] (D23). Sempre disponibilizamos formaçáo continuada a todos os professores, que por sinal participam muito de formaçóes (D30). Sempre é proporcionada pela escola espaços de formação planejados pela equipe diretiva em consonância com a necessidade e solicitaçáo dos professores (D32). Oferecemos formação continuada aos professores através de parcerias com a coordenadoria de ensino, a secretaria municipal de educação e a SEC e as atividades da comunidade (D51). Em relação à formação continuada, fizemos duas anualmente, mas carecemos de recursos para proporcionar algo novo, "aquele" diferencial (D52).
\end{abstract}

Em relação a como a gestão escolar deve encaminhar a formação continuada de docentes, Ferreira (2008, p. 109) destaca que "a formação de um profissional entendido como 'um mediador' da 'vida social' efetiva, das expectativas e do desejo coletivo de uma comunidade [...]" precisa ser desenvolvida por meio de uma reflexão crítica acerca da realidade social, econômica e humana, objetivando a organizaçáo de um Projeto Político e Pedagógico.

A Tabela 2 apresenta as indicações dos diretores pesquisados em relação às suas percepçóes quanto aos objetivos que a escola trabalha referente à educação ambiental, tendo indicaçóes semelhantes que quatro objetivos dos nove sugeridos tiveram indicaçóes semelhantes.

Tabela 3 - Objetivos da educação ambiental desenvolvidos na escola

\begin{tabular}{lc}
\hline \multicolumn{1}{c}{ Temáticas relacionada à gestáo - necessidades de mais estudo } & No de diretores \\
\hline Conscientizar alunos e comunidade para a plena cidadania & $46(88,4 \%)$ \\
Sensibilizar para o convívio com a natureza de forma mais harmônica & $44(84,6 \%)$ \\
$\begin{array}{l}\text { Desenvolver os processos de ensino e de aprendizagem (ensinar) para a } \\
\text { preservaçáo dos recursos naturais }\end{array}$ & $42(80,7 \%)$ \\
Promover o conceito de desenvolvimento sustentável & $42(80,7 \%)$ \\
Dialogar para a construção de sociedades sustentáveis & $40(76,9 \%)$ \\
Possibilitar uma compreensão crítica e complexa da realidade socioambiental & $40(76,9 \%)$ \\
\hline \multicolumn{2}{c}{ Total de marcaçóes } \\
\hline
\end{tabular}

Fonte: dos pesquisadores (2016). 
A Tabela 3 traz as informaçóes referentes aos objetivos em educação ambiental que cada escola desenvolve em que os diretores marcaram os cinco mais importantes. O objetivo "conscientizar alunos e comunidade para a plena cidadania" foi o que recebeu o maior número de indicaçóes, $88,4 \%$ dos diretores pesquisados. Esse processo de conscientização deve passar, segundo Gutiérrez e Prado (2002, p. 66), pela "interlocução, pela conversa, [...] a interlocução significativa, diálogo horizontal, ter sempre presente o outro como legítimo outro [...]". Nessa interlocução, deve ser oportunizada a participação da comunidade, pois conforme Giaretta, Fernandes e Philippi (2012, p. 529), a "populaçáo traz, por meio da participação, conhecimentos e experiências que the são inerentes e que, muitas vezes, são imperceptíveis ao poder publico local [...]".

O segundo objetivo mais indicado pelos diretores foi "sensibilizar para o convívio com a natureza de forma mais harmônica", recebendo $84,6 \%$ das indicaçóes dos diretores. Observa-se que a sensibilização depende de diversos fatores. Para Giaretta, Fernandes e Philippi (2012, p. 537), a "existência de informaçôes ambientais constitui ponto crucial para a educação/conscientização, capacitação e percepção dos impactos ambientais locais". Dessa forma, os autores destacam que as informaçôes acerca da temática ambiental precisam ser observadas também na escola.

A terceira indicação de objetivo trabalhado nas escolas, segundo os diretores, ficou dividida entre os objetivos "desenvolver o processo de ensino e de aprendizagem (Ensinar) para a preservaçáo dos recursos naturais" e "promover o conceito de desenvolvimento sustentável". Assim, observa-se que a preservaçáo dos recursos naturais e o conceito de sustentabilidade aparentemente estáo sendo desenvolvidos nas escolas. Guimarães Júnior (2011, p. 236) alerta para a necessidade de cuidar como a mídia, as ideologias e os interesses econômicos utilizam nos seus discursos expressóes como "sustentabilidade, desenvolvimento sustentável, responsabilidade socioambiental, [...] produção verde, consumo sustentável, desperdício zero, compromisso ecológico, dentre outras variantes desse viés de uma economia 'preocupada' com o bem-estar das pessoas e com a preservação da natureza".

Com uma postura mais crítica, em relação ao trabalho com a temática do desenvolvimento sustentável, Sauvé (2005, p. 320) alerta que a

[...] concepçâo utilitarista da educação e a representação 'recursista' do meio ambiente, adotada pela 'educaçáo para o desenvolvimento sustentável', mostram-se nitidamente reducionistas com respeito a uma educaçáo fundamental preocupada em otimizar a teia de relações entre as pessoas, o grupo social a que pertencem e o meio ambiente.

A Tabela 4 apresenta as respostas dos diretores quando questionados sobre quem são as iniciativas na realização de ações em educação ambiental nas escolas. 
Tabela 4 - Quem tem a iniciativa para as ações em educação ambiental

\begin{tabular}{lccc}
\hline $\begin{array}{c}\text { Quem tem iniciativa para as açóes em } \\
\text { educaçáo ambiental }\end{array}$ & Sim & Não & Eventualmente \\
\hline Grupos de professores & $46(88,5 \%)$ & $1(1,9 \%)$ & $5(9,6 \%)$ \\
Equipe diretiva da escola & $46(88,5 \%)$ & 0 & $6(11,5 \%)$ \\
Mantenedora & $35(67,3 \%)$ & $3(5,7 \%)$ & $14(27 \%)$ \\
Alunos & $34(65,4 \%)$ & $2(3,9 \%)$ & $16(30,7 \%)$ \\
Funcionários & $27(51,9 \%)$ & $5(9,6 \%)$ & $20(38,5 \%)$ \\
\hline
\end{tabular}

Fonte: dos pesquisadores (2016).

$\mathrm{Na}$ Tabela 4, consta no mesmo grau de indicação, correspondendo a 88,5\%, que grupos de professores e a equipe diretiva da escola têm a iniciativa de indicar as açóes de educação ambiental nas instituições de ensino. Isso mostra que em menor indicação se encontram os alunos como sujeitos e proponentes de açóes em educação ambiental, correspondendo 65,4\%. Em contrapartida, os alunos são envolvidos diretamente nas açóes em educação ambiental, no entanto, não são sujeitos dessas açóes. Loureiro (2002) destaca que a educação ambiental é um elemento estratégico na consciência crítica das relaçóes sociais.

$\mathrm{Na}$ Tabela 5 constam as informaçóes relacionadas aos atores envolvidos nas açóes em educação ambiental desenvolvidos nas instituições de ensino.

Tabela 5 - Atores envolvidos nas açóes em educação ambiental

\begin{tabular}{lccc}
\hline $\begin{array}{c}\text { Quais os atores envolvidos nas açóes em } \\
\text { educaçáo ambiental }\end{array}$ & Sim & Náo & Eventualmente \\
\hline Grupos de professores & $51(98,1 \%)$ & 0 & $1(1,9 \%)$ \\
Alunos & $47(90,4 \%)$ & 0 & $5(9,6 \%)$ \\
Equipe diretiva da escola & $45(86,5 \%)$ & 0 & $7(13,5 \%)$ \\
Funcionários & $39(75 \%)$ & $3(5,8 \%)$ & $10(19,2)$ \\
Mantenedora & $28(53,8 \%)$ & $8(15,4 \%)$ & $16(30,8 \%)$ \\
\hline
\end{tabular}

Fonte: dos pesquisadores (2016).

A Tabela 5 apresenta que, para a maioria dos diretores pesquisados, os principais atores envolvidos nas açóes em educação ambiental são: grupos de professores, alunos e equipe diretiva. Assim, se os alunos, conforme os dados da Tabela 4 não são sujeitos nesse processo, pode-se constatar que as "interpretaçóes decorrentes do processo de construção simbólica" (BARCELOS, 2005, p. 90) da educação ambiental podem estar em descompasso.

$\mathrm{Na}$ Tabela 5, o grupo de professores aparece como um dos mais envolvidos nas açóes em educação ambiental. Para Gutiérrez e Prado (2002, p. 65), essa indicação "implica que educador ou educadora, sem deixar de ser um 'ensinador' - e bom 'ensinador' - se preocupe e 
saiba promover uma aprendizagem com sentido, voltada à formação da cidadania ambiental na sociedade planetária”. O maior desafio da gestão escolar é promover e incentivar o desenvolvimento de práticas pedagógicas que favoreçam a aprendizagem com sentido.

A Tabela 6 apresenta as respostas dos diretores quando questionados sobre os temas e atores envolvidos nas ações em educação ambiental.

Tabela 6 - Tema em educação ambiental e atores envolvidos

\begin{tabular}{lccccc}
\hline $\begin{array}{c}\text { Temas em educaçáo } \\
\text { ambiental }\end{array}$ & Professores & Pais & Alunos & Outros & Total \\
\hline Água & $6(11,6 \%)$ & 0 & $44(84,6 \%)$ & $2(3,8 \%)$ & $52(100 \%)$ \\
Lixo e reciclagem & $6(12,7 \%)$ & $1(2,3 \%)$ & $38(80,8 \%)$ & $2(4,2 \%)$ & $47(90,3 \%)$ \\
Saúde e nutrição & $8(17,1 \%)$ & $3(6,4 \%)$ & $34(72,3 \%)$ & $2(4,2 \%)$ & $47(90,3 \%)$ \\
Plantio de árvores & $4(8,7 \%)$ & $5(10,8 \%)$ & $34(73,9 \%)$ & $3(10,7 \%)$ & $46(88,4 \%)$ \\
Plantas e animais & $6(13,3 \%)$ & $1(2,2 \%)$ & $35(77,8 \%)$ & $3(6,7 \%)$ & $45(86,5 \%)$ \\
\hline
\end{tabular}

Fonte: dos pesquisadores (2016).

A Tabela 6 apresenta os cinco principais temas trabalhados nas instituições de ensino e os atores envolvidos nesse processo, conforme as indicaçóes dos diretores pesquisados. O tema água foi o mais trabalhado nas escolas pesquisadas, envolvendo o maior número de alunos, com 84,6\%, sendo seguido pelo tema lixo e reciclagem com 80,8\%. Em contrapartida, o tema que envolveu o maior número de professores foi o de saúde e nutrição, com $17,1 \%$.

Quanto às temáticas, indicadas pelos diretores pesquisados, como as mais trabalhadas nas instituições de ensino percebe-se uma visão fechada. Conforme Cooper e Anjos (2014, p. 133) essa forma de fragmentar as questóes ambientais acaba "construindo dogmas relacionados a uma visão higienizante, biologizante e reducionista destas, e afastando-se do seu real sentido humanitário, o da crítica social". Dessa forma, os trabalhos desenvolvidos nas escolas, aparentemente, não trazem a transformação social.

Como forma de encaminhar a participação mais efetiva dos pais, e demais sujeitos da comunidade, em situaçóes que necessitem da tomada de decisão, Lück et al. (2011, p. 66) sugerem que "usar técnicas participativas para solucionar problemas e tomar decisóes encoraja a equipe escolar, [...], assim como os pais e alunos quando apropriado, a assumirem maiores responsabilidades com relação ao que acontece na escola, como também facilita uma melhor tomada de decisão”. Adotar formas alternativas de promover a participaçáo da comunidade escolar pode auxiliar no desenvolvimento desse trabalho.

\section{CONSIDERAÇÓES FINAIS}

A gestão escolar exerce papel importante na promoção do ensino desenvolvido nas escolas de educação básica, por meio do acompanhamento do trabalho pedagógico dos docentes. 
As reflexóes acerca da educação ambiental apresentam possibilidades de uma proposta de ensino mais crítica e problematizadora, podendo promover a articulaçáo entre o contexto local e o global, por meio do envolvimento e da participaçáo dos estudantes e demais agentes da comunidade escolar nas tomadas de decisóes nas instituiçóes de ensino.

A gestão escolar, como desencadeadora do processo democrático e participativo dentro das escolas, pode promover a possibilidade de desenvolvimento da conscientizaçáo ambiental, participativa e responsável dos docentes por meio de propostas de formação continuada inovadoras e discutidas com a comunidade escolar.

\section{REFERÊNCIAS}

ALVES, Wanderson F. Gestão escolar e o trabalho dos educadores: da estreiteza das políticas à complexidade do trabalho humano. Educaçáo \& Sociedade, Campinas, v. 31, n. 110, p. 17-34, jan.-mar. 2010. Disponível em: <http://www.cedes.unicamp.br>. Acesso em: 20 de jan. 2013.

BARCELOS, Valdo. H. L. "Escritura" do mundo em Octavio Paz: uma alternativa pedagógica em educação ambiental. In: SATO, Michèle.; CARVALHO, Isabel. C. M.

Educaçáo ambiental: pesquisas e desafios. Porto Alegre: Artmed, 2005.

BARDIN, Laurence. Análise de conteúdo. Lisboa: Edições 70, 2012.

BRASIL, Lei de Diretrizes e Bases da Educação Nacional, nº 9.394 de 20 de dezembro de 1996. $5^{\mathrm{a}}$ ed. 2010. Biblioteca Digital da Câmara dos Deputados. Centro de Documentação e Informação. Coordenação de Biblioteca. Disponível em: http:// bd.camara.gov.br. Acesso em: 15/03/2015.

BRASIL, Constituição da República Federativa do Brasil, de 1988. Biblioteca Digital da Câmara dos Deputados. Centro de Documentação e Informação. Coordenação de Biblioteca. Disponível em: http://bd.camara.gov.br. Acesso em: 15/03/2015.

CAPRA, Fritjof. A teia da vida: uma nova compreensão científica dos sistemas vivos. 10 ed. São Paulo: Cultrix, 2006.

CARVALHO, Isabel C. M. A questão ambiental e a emergência de um campo de ação político-pedagógica. In: LOUREIRO, Carlos F. B.; LAYRARGUES, Philippe P.; CASTRO, Ronaldo S. de (org.). Sociedade e meio ambiente: a educação ambiental em debate. 6 ed. São Paulo: Cortez, 2010.

A invenção do sujeito ecológico: identidade e subjetividade na formação dos educadores ambientais. In: SATO, Michèle; CARVALHO, Isabel. C. M. Educaçáo ambiental: pesquisas e desafios. Porto Alegre: Artmed, 2005.

CHEMIN, Beatris. F. Manual da Univates para Trabalhos Acadêmicos: planejamento, elaboração e apresentação. 2 ed. Lajeado: Ed. Da Univates, 2012. 
COOPER, Aline de F. S. C. ; ANJOS, Maylta B. dos . A constituição do pensamento ambiental: de Leff a Ingold - bases da visão crítica? Pesquisa em Educação

Ambiental, vol. 9, n. 2, p. 133-146, 2014. Disponível em: <https://www.researchgate. net/.../291017919>. Acesso em: 16 nov. 2015.

CÓSSIO, Maria de F. Gestão democrática da educação: retórica política ou prática possível. In: CAMARGO, Ieda de. Gestáo e política da educaçáo. Santa Cruz do Sul: EDUNISC, 2006.

CURY, Carlos R. J. Gestão democrática dos sistemas públicos de ensino. In: OLIVEIRA, Maria A. M. de (org.). Gestáo educacional: Novos olhares, novas abordagens. 9 ed. Petrópolis, RJ: Vozes, 2012.

DELORS, Jacque (org.). Educação: Um tesouro a descobrir. Relatório para a UNESCO da Comissão Internacional sobre Educação para o século XXI. 4a . Ed. São Paulo: Cortez; Brasília, DF: MEC: UNESCO, 2000.

DEMO, Pedro. Metodologia da investigação em educaçáo. Curitiba: Ibepex, 2005. Metodologia cientifica em ciências sociais. 3 ed. São Paulo: Atlas, 2014.

DIAS, Donaldo de S.; SILVA, Mônica F. da. Como escrever uma monografia: manual de elaboraçáo com exemplos e exercícios. São Paulo: Atlas, 2010.

DIEHL, Astor A.; TATIM, Denise C. Pesquisa em ciências sociais aplicadas: métodos e técnicas. São Paulo: Pearson Prentice Hall, 2004.

FERREIRA, Naura S. C. A gestão da educação e as políticas de formação profissionais da educação: desafios e compromisso. In: (org.). Gesta democrática da educação: atuais tendências, novos desafios. 6 ed. São Paulo: Cortez, 2008.

FREIRE, Paulo. Pedagogia da autonomia: saberes necessários à prática educativa. São Paulo: Paz e Terra, 2010.

A sombra desta mangueira. São Paulo: Olho D’água, 1995.

GADOTTI, Moacir (org.). Perspectivas Atuais da Educaçáo. Porto Alegre: Artmed, 2000.

GIARETTA, Juliana B. Z.; FERNANDES, Valdir; PHILIPPI JR, Arlindo. Desafios e condicionantes da participação social na gestão ambiental municipal no Brasil.

Organizaçóes \& Sociedade, Salvador, v. 19, n. 62, p. 527 - 548, jul./set., 2012.

Disponível em: <www.revistaoes.ufba.br>. Acesso em: 24 fev. 2015.

GIL, Antonio Carlos. Métodos e técnicas de pesquisa social. 6 ed. São Paulo: Atlas, 2012. 
. Como elaborar projetos de pesquisa. 5 ed. São Paulo: Atlas, 2010.

GONÇALVES, Marco A. G. A prática da gestão escolar como elemento facilitador/ propulsor do sucesso da escola. Revista Científica Intr@ciência. Ano 2, no 1, p.72-105, Nov. 2010. Disponível em: <www.faculdadedoguaruja.edu.br/revista/edicoesAnteriores/ edicao22010.asp>. Acesso em: 14 mar. 2013.

GONZÁLEZ- GAUDIANO, Edgar. Interdisciplinaridade e educação ambiental: explorando novos territórios epistêmicos. In: SATO, Michèle; CARVALHO, Isabel C. M. Educaçáo ambiental: pesquisa e desafios. Porto Alegre, RS: Artmed, 2005.

GUILHERME, Ricardo; FISCHER, Julianne. O Papel da Gestão Escolar nos processos de ensinar e aprender história e geografia nos anos inicias. Revista Interdisciplinar Aplicada Blumenau, v.5, n.4, p.49-62 ,TRI IV, 2011. Disponível em: <www.rica.unibes. com.br/index.php/rica/article/viewFile/437/368>. Acesso em: 30 jul. 2015.

GUIMARÁES JÚNIOR, Isaac de S. De volta ao mundo das ideias: o fetichismo ambiental no discurso midiático da sustentabilidade. Comunicaçáo e Sociedade, ano 33, n. 56, p. 233 - 263, jul./dez., 2011. Disponível em: <https://www.metodista.br/revistas/ revistas-ims/index.php/CSO/article/.../2290/2761>. Acesso em: 14 mar. 2013.

GUTIÉRREZ, Francisco; PRADO, Cruz. Ecopedagogia e cidadania planetária. 3. ed. Guia da Escola Cidadá, São Paulo: Cortez, Instituto Paulo Freire, v. 3, 2002.

JUNQUILHO, Gelson S., ALMEIDA, Roberta A de e SILVA, Alfredo R. L. da. As "artes do fazer" gestão na escola pública: uma proposta de estudo. Cadernos EBAPE. BR, Rio de Janeiro, v. 10, n. 2, artigo 5, jun. 2012. Disponível em: <www.scielo.br/scielo. php?script=sci_arttext\&pid=S1679-39512012000200006>. Acesso em: 14 mar. 2013.

LACERDA, Ana B. de. Educação ambiental entre o humano, o não humano e o desumano. In: TRISTÃO, Martha; JACOBI, Pedro R. Educaçáo ambiental e os movimentos de um campo de pesquisa. São Paulo: Annablume, 2010.

LEFF, Enrique. Racionalidade ambiental: a reapropriação social da natureza. Rio de Janeiro: Civilização Brasileira, 2006.

LÜCK, Heloísa et al. A escola participativa: o trabalho do gestor escolar. 9 ed. Rio de Janeiro: Vozes, 2011.

LÜCK, Heloísa. Gestão educacional: uma questão paradigmática. 2 ed. Rio de Janeiro: Vozes, 2006.

MARCONI, Marina de A.; LAKATOS, Eva M. Fundamentos de Metodologia Científica. 7 ed. São Paulo: Atlas, 2010. 
MELLO, Elena M. B.; CÓSSIO, Maria de F. Gestão da educação Básica: ausências e emergências. In: CAMARGO, Ieda de. Gestáo e política da educaçáo. Santa Cruz do Sul: EDUNISC, 2006.

OLIVEIRA, Marco A. de. Gestão e pedagogia empreendedoras urgem Educadorempreendedor. Revista de Educação, Cultura e Comunicação Social, [S.l.], v. 1, n. 2, p. 55-60, jul./dez., 2010. Disponível em: publicacoes.fatea.br/index.php/eccom/article/ view/407/263. Acesso em: 14 mar. 2013.

OLIVEIRA, Maria A. M. de et all. Projeto político-pedagógico: da construção à implementação. In: OLIVEIRA, Maria A. M. de (org.). Gestáo educacional: Novos olhares, novas abordagens. 9 ed. Petrópolis, RJ: Vozes, 2012.

PARO, V. H. Gestáo escolar, democracia e qualidade do ensino. São Paulo: Ática, 2007.

ROSA, Daiani C. da. Formação docente e a educação ambiental: desafios atuais. In: MAZZARINO, Jane (org.). Educação, meio ambiente e comunicação: reflexóes, investigaçóes e propostas. Caderno Pedagógico, Lajeado, RS: FATES, v. 6, n. 1, 2009.

SANTOS, Silvio C. dos. Uma visão diacrônica da díade: escola e gestão. Revista de Educaçáo do IDEAU, [S.1.], v. 5, n. 11, jan./ jun. 2010. Disponível em: <http://www. ideau.com.br/getulio/restrito/upload/revistasartigos/172_1.pdf>. Acesso em: 29 fev. 2016.

SATO, Michèle; CARVALHO, Isabel C. de M. Educação ambiental: pesquisa e desafios. Porto Alegre: Artmed, 2005.

SAUVÉ, Lucie. Educação ambiental: possibilidades e limitações. Educaçáo e Pesquisa, São Paulo, v. 31, n. 2, p. 317 - 322, mai./ago. 2005. Disponível em: <www.foar.unesp. $\mathrm{br} /$.../sauve-ea-possibilidades-limitacoes-meio-ambiente---tipos.pdf>. Acesso em: 20 mar. 2013.

SCHNECKENENBERG, Marisa. Democratização da gestão e atuação do diretor de escola municipal. Revista Brasileira de Política e Administração da Educaçáo, [S.1.], v. 25, n. 1, p. 115-137, jan./abr. 2009. Disponível em: <http://seer.ufrgs.br/rbpae/article/ view/19330>. Acesso em: 30 jul. 2015.

SILVA, Maraisa P. S. da. A re-configuração das atribuiçóes do diretor escolar com a instauração do regime de gestáo democrática da escola. Dissertação. Programa de PósGraduação em Educação, da Faculdade de Filosofia e Ciências, Universidade estadual Paulista Júlio de Mesquita Filho, Campus de Marília, 2011. Disponível em: https://www. marilia.unesp.br/Home/Pos-Graduacao/.../silva_mps_me_mar.pdf Acesso em: 27 fev. 2015. 
TRISTÃO, Martha; JACOBI, Pedro R. A educação ambiental e os movimentos de um campo de pesquisa: entre, através e além do ambientalismo e da educação. In:

. Educaçáo ambiental e os movimentos de um campo de pesquisa. São Paulo: Annablume, 2010.

VIEIRA, Alexandre T.; ALMEIDA, Maria E. B. de; ALONSO, Myrtes (org.). Gestáo educacional e tecnologia. São Paulo: Avercamp, 2003. 